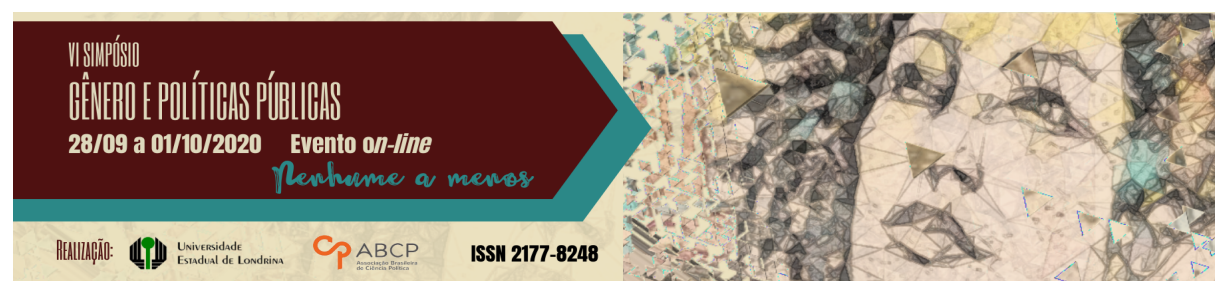

\title{
Mulheres nas ciências exatas: estratégias de inclusão e desenvolvimento
}

\author{
Andreia dos Santos Barreto Monsores de Assumpção ${ }^{1}$
}

\begin{abstract}
Resumo
O presente trabalho visa apresentar reflexões sobre a histórica desigualdade de participação entre mulheres e homens na educação superior brasileira, especialmente nas ciências exatas, as chamadas STEM, do inglês Science, Technology, Engineering and Mathematics ou Ciência, Tecnologia, Engenharia e Matemática. Ademais, é objetivo também refletir sobre os esforços realizados nos últimos anos para equidade de gênero na educação. A ideia é observar o caminho percorrido pelos estudos de gênero, especialmente os que privilegiam a temática do trabalho de reprodução e de produção social, observando a apropriação de tais contribuições na elaboração e implementação de políticas públicas educacionais com foco redução das assimetrias de entre mulheres e homens nas diversas instâncias da vida social.
\end{abstract}

Palavras-chave: desigualdade de gênero; educação superior; ciências; políticas públicas

\section{Woman in Stem Fields: participation strategies and progress}

\begin{abstract}
This paper aims to present reflections about the historical inequality of participation between women and men in Brazilian science, especially in the exact sciences, the STEM, Science, Technology, Engineering and Mathematics. It is also an objective to reflect on the efforts made in recent years for gender \footnotetext{
andreiabarr@gmail.com. https:/ / orcid.org/0000-0003-2957-1440

GT 18 - Políticas públicas de gênero no Brasil do século XXI: avanços e desafios
}

1 Cientista Social, doutoranda em Ciências Sociais/PPGCS/UFRRJ -
\end{abstract}


equity in education.. The idea is to observe the path taken by gender studies, especially those that privilege the theme of reproductive work and social production, observing the appropriation of such contributions in the elaboration and implementation of educational public policies with a focus on reducing the asymmetries between women and men. men at different levels of social life.

Keywords: gender inequality; college education; science; public policies

O presente trabalho visa refletir sobre a histórica desigualdade de gênero na educação superior brasileira, com foco na inserção das mulheres nas ciências. O objetivo é analisar sobre os esforços realizados nos últimos anos para a redução desigualdade de participação e de desempenho na educação, especialmente nas ciências exatas, as chamadas STEM, do inglês Science, Technology, Engineering and Mathematics ou Ciência, Tecnologia, Engenharia e Matemática, em português.

De acordo com relatório "Decifrar o código: educação de meninas e mulheres em ciências, tecnologia, engenharia e matemática (STEM)", a Agenda 2030 das Nações Unidas para o Desenvolvimento Sustentável, aprovada em setembro de 2015 na Assembleia da ONU, sustenta a necessidade de novas abordagens no enfrentamento das questões ambientais sociais e econômicas, neste sentido, a participação efetiva das mulheres nas diversas áreas do conhecimento, além de perspectiva da inclusão, abre espaço para novas visões e soluções, a partir de diferentes pontos de vista e conhecimentos. A Agenda conta com dezessete Objetivos de Desenvolvimento Sustentável (ODS), incluindo o ODS 4, sobre educação, e o ODS 5, sobre igualdade de gênero, entretanto, as áreas STEM, por sua capacidade de inovação, alcançam outros objetivos, como o desenvolvimento da agricultura, as questões climáticas, a gestão sustentável de água e saneamento, o acesso sustentável à energia, entre outros.

O relatório "Decifrar o código" mostra também que o acesso de meninas e mulheres jovens à educação tem aumentado em todo o 
mundo. Em 2014, a paridade de gênero foi atingida na educação primária mundial. Entretanto, do contingente estudantil de mulheres na educação superior nos diferentes países, apenas 30\% escolheram campos de estudo relacionados à área STEM. As matrículas de mulheres são mais baixas em Tecnologia da Informação e Comunicação, as chamadas TICs, (3\%), ciências naturais, matemática e estatística (5\%) e engenharia, produção industrial e construção (8\%); as mais altas estão nos cursos de saúde e bem-estar (15\%). No caso brasileiro o cenário não é diferente, e mesmo com a participação maciça feminina nos diversos estágios educacionais, a desigualdade entre homens e mulheres nas variadas carreiras e áreas do conhecimento é notável.

A participação da mulher na educação brasileira tem sido apresentada e discutida por pesquisadoras clássicas como Fúlvia Rosemberg (1982, 1994, 2001), Guacira Lopes Louro (1997), Marília Carvalho (2001, 2012) e diferentes análises evidenciam as desigualdades no processo de escolarização de meninas e meninos, assim com o relacionamento do gênero com outras categorias sociais como raça, classe e origem regional. No geral, as meninas têm melhor desempenho escolar, são menos repetentes, apresentam menor defasagem sérieidade, ficam menos em recuperação e apresentam menor índice de evasão. A pesquisadora Marília Carvalho (2001) pondera que os indicadores de desempenho escolar são influenciados pelas políticas educacionais e por fatores subjetivos e relacionais:

as estatísticas de desempenho escolar têm alguma relação com a aprendizagem dos alunos, porém essa relação é intermediada: pelas políticas educacionais - que podem, por exemplo, levar a fortes pressões pela diminuição drástica do número de reprovados, ou mesmo de indicados para atividades de recuperação; pelo relacionamento entre professores, professoras, alunos e alunas, sempre perpassado por um conjunto de desigualdades sociais como aquelas decorrentes de relações raciais, de classe e de gênero; assim como pelos critérios de avaliação adotados explícita ou implicitamente, mais ou menos conscientemente pelos encarregados de avaliar e 
atribuir conceitos ou notas aos alunos (CARVALHO, 2001, p. 555).

Guacira Louro (1997) questiona a "naturalização" das práticas que distinguem as crianças por gênero, e que muitas vezes são ratificadas pela escola como uma forma correta de conduta. A separação de meninos e meninas nos grupos de trabalho, a diferença nos brinquedos e nas brincadeiras, até mesmo no espaço ocupado durante as atividades em grupo. Assim, a pesquisadora questiona:

É de esperar que os desempenhos nas diferentes disciplinas revelem as diferenças de interesse e aptidão "características" de cada gênero? Sendo assim, teríamos que avaliar esses alunos e alunas através de critérios diferentes? (...) precisamos aceitar que os meninos são "naturalmente" mais agitados e curiosos do que as meninas? E quando ocorre uma situação oposta à esperada, ou seja, quando encontramos meninos que se dedicam a atividades mais tranquilas e meninas que preferem jogos mais agressivos, devemos nos "preocupar", pois isso é indicador de que esses/as alunos/as estão apresentando "desvios" de comportamento? (LOURO, 1997, p. 63-4)

A socialização distinta entre meninos e meninas fora do ambiente escolar influencia sobremaneira a experiência de aprendizagem. Para Pierre Bourdieu, o sucesso acadêmico também está subordinado às "relações entre o sistema de ensino e a estrutura das relações entre as classes" (BOURDIEU, 2009, p. 16). Segundo o autor, a instituição escolar não é uma instância neutra, que transmite uma forma de conhecimento intrinsecamente superior e que avalia os estudantes a partir de critérios universalistas, mas, ao contrário, é uma instituição a serviço da reprodução e legitimação da dominação exercida pelas classes privilegiadas, onde a origem social dos estudantes (sexo, etnia, classe, local de moradia, etc.) tem um peso considerável.

A desigualdade de gênero enraizada no processo educacional prejudica e limita o pleno acesso ao desenvolvimento humano e social. 
O limite do escopo de atuação das meninas é apontado por Moema Guedes (2008) como fruto da ideia de que as meninas teriam mais propensão às artes e à literatura (facilidade nas disciplinas articuladas à sensibilidade e emoção), enquanto os meninos apresentariam mais aptidão nas ciências, devido a sua maior racionalidade, e "esse tipo de visão acaba se convertendo em uma espécie de profecia autorrealizável, em que todos os casos 'desviantes' não são devidamente estimulados" (GUEDES, 2008, p. 120).

No Brasil, é notório o crescimento da participação das mulheres na educação superior, em todas as áreas do conhecimento, entretanto, o desafio da superação de distinções que evocam a tradicional divisão sexual do trabalho permanece. No ensino superior, o desafio da democratização se apresenta em, pelo menos, dois momentos: na escolha da carreira e na limitação da evolução progressiva na área escolhida. Dados do Censo da Educação Superior, do ENADE e do $\mathrm{CNPq}$, mostram que a desigualdade de gênero está enraizada na própria academia, em suas esferas mais qualificadas (Barreto, 2014). Ainda que as mulheres apresentem melhor desempenho desde o período escolar, que sejam maioria entre ingressantes e formandos universitários, elas estão majoritariamente concentradas em determinadas áreas do conhecimento, e mesmo nesses guetos, têm um limitador que restringe a ascensão aos postos mais altos de comando e prestígio dentro de seu escopo profissional. Cursos como Terapia Ocupacional, Nutrição e Serviço Social contavam com mais de 90\% de mulheres em 2010. E cursos como Tecnologia em Automação Industrial, Tecnologia em Manutenção Mecânica e as Engenharias Aeroespacial, Aeronáutica, Automotiva, Mecânica e Naval, inversamente, contavam com mais de 90\% de homens em 2011 (BARRETO, 2014, p. 27-28). Tal fenômeno não é registrado nas apenas entre estudantes, mas também na carreira docente na universidade, em entidades públicas ou privadas, entre pesquisadores e cientistas, dirigentes de entidades de educação superior e reitores. Um interessante indicador explorado por Moema Guedes, Nara Azevedo e Luiz Otávio Ferreira (2015) diz 
respeito à predominância masculina ou feminina na distribuição das Bolsas de Produtividade do $\mathrm{CNPq}$, que contempla a elite da ciência brasileira. Os pesquisadores concluíram que o desequilíbrio de gênero identificado na entrada dos cursos, se reflete também na ocupação dos postos de maior prestígio do desenvolvimento da carreira:

Naquelas em que as mulheres constituem a maioria entre os "iniciantes" constata-se o equilíbrio e/ou a predominância feminina, como no caso da Saúde Coletiva e da Psicologia. Em casos como o da Medicina Veterinária ou das engenharias de Produção e Operacional, em que os homens são maioria consolidada [...], o fenômeno é oposto, não se vislumbrando um equilíbrio a médio e longo prazos (GUEDES; AZEVEDO; FERREIRA, 2015, p. 381).

No mercado de trabalho a desigualdade aparece também nos postos mais importantes de tomada de decisão e os mais bem remunerados, entre supervisores, diretores e presidentes. Dados apresentados pela pesquisa "Educação, ciclo de vida e desigualdade de gênero no mercado de trabalho formal brasileiro" mostram que a desigualdade de gênero aumenta de acordo com o nível de escolaridade e que para universitários, a diferença é quase o dobro da diferença observada para trabalhadores com ensino médio incompleto: "aos 40 anos de idade, mulheres sem diploma de ensino médio ganhavam em média 28,8\% menos que homens como mesmo nível educacional, ao passo que no grupo com ensino médio e nível universitário, esta diferença foi de 32,6\% e 47,4\%" (MACHADO; NERI; PINHO NETO, 2017). A desigualdade surge também na quantidade de horas trabalhadas e na diferenciação salarial, visto que as mulheres ainda percebem, em média 76,5\%, dos rendimentos masculinos e, contando com dupla jornada, trabalham em média 3 horas a mais que os homens².

2 https://agenciadenoticias.ibge.gov.br/agencia-noticias/2012-agencia-denoticias/noticias / 20234-mulher-estuda-mais-trabalha-mais-e-ganha-menos-do-que-ohomem $(05 / 12 / 2018)$ 
De acordo com Helena Hirata e Daniele Kergoat (2007, p. 596), os estudos feministas têm apontado, há pelo menos quatro décadas, para o conceito de divisão sexual do trabalho, no entanto este assunto continua em aberto. A despeito da compreensão sobre a natureza, a origem e as possíveis formas de superação, a realidade é que o cenário muda muito lentamente. Esta divisão se apresenta tanto na distribuição das oportunidades do mercado de trabalho, como no compartilhamento das responsabilidades pela vida reprodutiva, ou seja, pelas tarefas domésticas.

O quadro atual é de reconfiguração das relações sociais, de questionamento sobre o papel da mulher e de sua necessidade financeira e desejo em ter uma carreira profissional, aliada as reflexões sobre a questão da maternidade e da manutenção de uma família. Em paralelo, há uma revisão sobre o papel do homem, como profissional, pai, "chefe de família" e como único provedor. Sem desconsiderar outras consequências, a conjuntura apresenta uma maior participação feminina no mercado assalariado, contudo, esta participação mantém as mulheres em posições com menos prestígio social e com a sobrecarga da jornada de trabalho duplicada pelo trabalho doméstico não remunerado.

Claudia Fonseca (1995) ao analisar a "família moderna" reflete sobre o peso do individualismo na negociação dos papéis sociais no mundo capitalista:

Hoje mal toleramos o peso dos papéis sociais as obrigações acarretadas pelo status de esposo, filho, etc. Considera-se que cada um tem o direito (senão a obrigação) de buscar a "autorrealização", de desenvolver sua individualidade e de se descobrir enquanto indivíduo singular, inimitável, insubstituível (FONSECA, 1995, p. 76).

A manutenção da família é traduzida na responsabilidade com as tarefas domésticas, com o cuidado das crianças, dos idosos e a preservação de um ambiente propício para a demais atividades sociais ou profissionais que as pessoas envolvidas porventura desenvolvam. $\mathrm{O}$ 
aprofundamento de uma ideia de sociedade baseada na autorrealização e no individualismo, como um ideal de felicidade, ao mesmo tempo tendo a família conjugal como um modelo a ser perseguido, acentua o desequilíbrio de oportunidades e responsabilidades entre mulheres e homens, uma vez que, de fato, as mulheres são socializadas para a manutenção da vida coletiva e os homens para a autorrealização através do trabalho remunerado. Neste contexto, os pressupostos que construíram a noção de trabalho feminino e masculino são tensionados, provocando novas reflexões sobre as relações de gênero, a imbricação do sistema capitalista versus a produção da vida.

Estudos recentes mostram que o trabalho doméstico continua sendo majoritariamente feminino. De acordo com relatório da ONG britânica OXFAM3, publicado em janeiro de 2020, como subsídio para a reunião anual do Fórum Econômico Mundial, ocorrido em Davos na Suíça (21 a 24/01/2020), em todo mundo 42\% das mulheres estão fora do mercado de trabalho, frente a $6 \%$ dos homens. Esta discrepância mostra que o trabalho do cuidado não remunerado pesa na contabilidade da exclusão e do empobrecimento feminino. O resultado, segundo o relatório, é que meninas que realizam trabalho não remunerado reiteradamente apresentam taxas de frequência escolar mais baixas do que as demais meninas. E que a diferença de renda entre mulheres e homens aumenta no auge da idade produtiva e reprodutiva das mulheres. Dados brasileiros mostram que as mulheres são as mais sacrificadas pela chamada dupla jornada. De acordo com a Pnad contínua do $3^{\circ}$ trimestre de 20194 , a jornada de trabalho feminina é de 53,3 horas semanais em média, enquanto a masculina alcança 50,2 horas por semana em média. A falta de tempo aumenta ainda mais o fosso de gênero, mas não é o único empecilho, o preconceito com o trabalho feminino ainda exclui e alija as mulheres do mercado de trabalho static.s3.amazonaws.com/cms/files/115321/1579272776200120_Tempo_de_Cuidar_P T-BR_sumario_executivo.pdf (janeiro/2020)

4 https://www.ibge.gov.br/estatisticas/sociais/habitacao/17270-pnadcontinua.html $=\& \mathrm{t}=$ series-historicas $($ janeiro $/ 2020)$ 
remunerado. A Pnad mostrou também que com a crise econômica que o Brasil enfrenta nos últimos anos, a taxa de desemprego feminino é maior, $13,9 \%$ para as mulheres e $10 \%$ para os homens. As mulheres também são mais afetadas pelo desemprego de longo prazo, e 28,8\% das desempregadas estão nessa situação há pelo menos dois anos. No caso dos homens, o percentual é de $20,3 \%$.

Os dados da desigualdade de gênero no mundo do trabalho corroboram a reflexão que Hirata e Kergoat fazem ao afirmar que a divisão sexual do trabalho é muito mais do que um resultado da relação entre os sexos e seus papéis, mais do que isso, é

um fator prioritário para a sobrevivência da relação social entre os sexos. Essa forma é modulada histórica e socialmente. Tem como características a designação prioritária dos homens à esfera produtiva e das mulheres à esfera reprodutiva e, simultaneamente, a apropriação pelos homens das funções com maior valor social adicionado (políticos, religiosos, militares etc.) (HIRATA; KERGOAT, 2007, p. 599).

Historicamente, esta responsabilidade pela reprodução da vida conferida às mulheres sustenta uma estrutura social que, de acordo com Fonseca (1995), apresenta diversas vantagens no que diz respeito a ordem pública, uma vez que oferece um lar e uma família para as crianças, para os operários (em contraposição ao bar), além de reduzir possíveis associações e rebeliões de trabalhadores que têm menos espaços de sociabilidade fora o local de trabalho. Aliás, a família é reconhecidamente um dos espaços mais importantes para a formação da cidadania, por ser socializadora das futuras gerações, por isso é objeto de disputa por instituições como Estado e igreja ${ }^{5}$.

\footnotetext{
5 Estas duas instituições, assim como a escola, os esportes, e o sistema de comunicação, ou seja, instâncias estruturantes das sociedades modernas, possuem uma dimensão simbólica da dominação masculina, traduzida por estruturas de pensamento ditas "naturais", mas que são fruto de coerção social, configurando a chamada violência simbólica. A dimensão simbólica acaba por legitimar o que ocorre na prática, onde a ordem sexual vigente relega a mulher a um papel inferiorizado (Bourdieu, 1998).
} 
O histórico processo de socialização de mulheres e homens é questionado pela literatura feminista, que discute a opressão e a dominação masculina e a influência nas escolhas pessoais que acabam por alimentar uma moral firmada na obediência, o que recai totalmente no pressuposto capitalista do individualismo e das escolhas pessoais. Para Flavia Biroli (2012), a construção social da desigualdade entre os sexos é um dos questionamentos do feminismo, que discute a naturalização das diferenças

entre traços psíquicos, desejos, competências e comportamentos de mulheres e homens, tomados como uma derivação das diferenças entre os sexos, isto é, das diferenças fisiológicas. Por meio dela (a naturalização as diferenças), convenções e normas manteriam as mulheres atadas à moral da obediência sem que isso representasse uma contradição ou fissura nas normas e instituições orientadas pelo ideal da autonomia (BIROLI, 2012, p. 9).

Este ponto é fundamental, pois significa dizer que as escolhas individuais estão circunscritas a um conjunto de fatores que perpassam, para não dizer que têm início, com a condição fundamental que é o gênero do indivíduo. Assim, as hierarquias entre mulheres e homens alicerçam as escolhas, as preferências e as identidades, reafirmando a posição de subordinação e vulnerabilidade relativa das mulheres. Para Biroli (2012, p. 12), essa é uma das bases para “a crítica à consideração das preferências já produzidas como um ponto de partida para as análises e a formulação de políticas".

A ampliação desde espectro de análise é o entendimento da indissociabilidade do gênero com outros marcadores da diferença, especialmente raça e classe. $\mathrm{O}$ conceito de interseccionalidade, difundido pela jurista norte-americana Kimberlé Crenshaw (1989), caracteriza a interdependência dessas três dimensões das relações de poder, e remonta, como relatado por Hirata (2014, p. 62). No caso brasileiro, é crucial abordar de forma interseccional a problemática do racismo, que é estrutural. Lélia Gonzáles (2019) afirma que a premissa 
constitucional de que todos são iguais perante a lei é puro formalismo. Na América Latina, no racismo mantém negros e índios na condição de subordinados, nas classes mais exploradas, através da persistente teoria do branqueamento.

Veiculada pelos meios de comunicação de massa e pelos aparelhos ideológicos tradicionais, ela reproduz e perpetua a crença de que as classificações e os valores do Ocidente são os únicos verdadeiros e universais. Uma vez estabelecido, o mito da superioridade branca demonstra sua eficácia pelos efeitos de estilhaçamento, de fragmentação da identidade racial que ele produz: o desejo de embranquecer (de "limpar o sangue", como se diz no Brasil) e internalizado, com a simultânea negação da própria raça, da própria cultura (GONZÁLES, 2019, p. 346).

Desta forma, não seria o caso de questionar somente as relações entre homens e mulheres, mas também é de importância central, analisar os casos das mulheres negras, brancas e dos homens negros e brancos, nos diversos âmbitos da vida social.

A consubstancialidade, segundo Daniele Kergoat (2010) tem estreita ligação com as desigualdades advindas do sistema capitalista, na relação entre dois grupos sociais antagônicos. A autora afirma que toda relação social é conflituosa e, no caso específico das relações sociais de sexo, surge um paradoxo: "simultaneamente à melhora da situação da mulher, em particular no mercado de trabalho, ocorre a persistência, às vezes mesmo a intensificação, da divisão sexual do trabalho", Kergoat (2010, p. 94). Isso ocorre porque as relações sociais possuem valor equivalente: ao se desenvolverem, as relações sociais de classe, gênero e raça se reproduzem e se coproduzem mutuamente. Consequentemente,

a participação da mulher no mercado de trabalho aumenta, mas as segmentações, horizontais e verticais, entre empregos masculinos e femininos, perduram. As desigualdades de salário persistem, e as mulheres continuam a assumir $o$ trabalho 
doméstico. A meu ver, no entanto, isso não representa nenhuma aporia ou contradição interna às relações sociais de sexo, mas aponta para o fato de que o capitalismo tem necessidade de uma mão-deobra flexível, que empenhe cada vez mais sua subjetividade: o trabalho doméstico assumido pelas mulheres libera os homens e, para as mulheres de alta renda, há a possibilidade de externalização do trabalho doméstico para outras mulheres (KERGOAT, 2010).

Para a autora, as relações sociais formam um nó que não pode ser desatado no nível das práticas sociais, mas apenas na perspectiva da análise sociológica. Entretanto, todos estes esforços visam compreender melhor as relações sociais e seus entrelaçamentos. Esse conhecimento é um caminho para a superação das diferentes opressões, subordinações que limitam a vida de mulheres, de meninas, homens e meninos, que são impelidos a fazer escolhas e a assumir papeis rígidos de gênero, em uma díade opressores/submissas.

Conforme reafirmam Clara Araújo et al (2018), ser mulher ou ser homem não tem conotação social neutra, menos ainda equivalente. As relações de gênero são pautadas por assimetrias de poder e por uma desigualdade histórica, que define a priori os papeis sociais: o mundo público para os homens e o âmbito privado para as mulheres. A diferença entre os gêneros interfere nas trajetórias dos indivíduos ao longo da vida e as mulheres são as mais oprimidas e limitadas.

A partir deste pressuposto, a partir de 2003, com a ascensão do Partido dos Trabalhadores ao comando do poder executivo, quando da posse do governo do Presidente Luiz Inácio da Silva, houve um momento de reconfiguração da estrutura da gestão federal com a instituição de uma Secretaria de Políticas para as Mulheres e de uma Secretaria de Políticas de Igualdade Racial, ambas com status de ministério. A partir de então, houve a adoção de uma série de políticas públicas com base na condição de gênero, visando o combater da desigualdade social. Conforme apresentado por Layla Carvalho (2018), a base conceitual para a criação das políticas para as mulheres era 
pautada pela concepção de transversalidade. $O$ conceito de transversalidade na gestão pública é entendido como um instrumento de intervenção social para situações específicas que demandam uma abordagem multidimensional e integrada, atravessando vários campos de análise. Nesta perspectiva, o governo federal do Brasil assumiu o compromisso de abordar de maneira sistemática as desigualdades de gênero em todas as políticas públicas. Para alcançar este mega objetivo, foi criada a Secretaria de Políticas para as Mulheres e ampliado o escopo de atuação do Conselho Nacional dos Direitos da Mulher. Estas duas instâncias institucionais tiveram como responsabilidade, não apenas criar políticas para as mulheres, mas viabilizar e criar estratégias para que os demais órgãos do governo federal, incluindo os próprios ministérios, e ainda os orçamentos anuais "fossem espaços de problematização das desigualdades de gênero, no sentido preconizado pelos debates sobre desigualdades de gênero nas políticas públicas" (CARVALHO, 2018, p. 88).

Lourdes Bandeira (2004) salientou que historicamente as políticas públicas no Brasil são, no geral, para mulheres, não adotam necessariamente a perspectiva de gênero. As políticas de gênero, segundo a autora, inegavelmente, deveriam abarcar "a diversidade dos processos de socialização para homens e para mulheres, cujas consequências se fazem presentes, ao longo da vida, nas relações individual e coletiva" (BANDEIRA, 2004, p. 10). Já as políticas para as mulheres centram esforços no feminino enquanto parte da reprodução social,

isso implica que não priorizam a importância e o significado que se estabelece no relacionamento entre os sexos; ao contrário, a centralidade posta na mulher-família reafirma a visão essencialista de que a reprodução e a sexualidade causam a diferença de gênero de modo simples e inevitável. Configura-se, portanto, numa política pública que enfatiza a responsabilidade feminina pela reprodução social, pela educação dos filhos, pela demanda por creches, por saúde e outras necessidades que garantam a 
manutenção e permanência da família e não necessariamente seu empoderamento e autonomia. (BANDEIRA, 2004, p. 10).

Ainda segundo a autora, a Política da Promoção da Igualdade de Gênero, impulsionada pela Secretaria de Políticas para as Mulheres, quando implementada, fazia parte de um escopo maior de programas para a redução da pobreza, e formavam um conjunto com políticas de transferência de renda, como o Bolsa Família e as políticas de promoção da igualdade racial. A expectativa era que as políticas de gênero, em uma perspectiva relacional entre mulheres e homens, tivessem lugar em ações futuras. A ideia, naquele momento, era incorporar a discussão de gênero nas instâncias burocráticas do Estado Brasileiro, tendo como base a inclusão do objetivo principal "promoção da igualdade social", a meta "promover a redução das desigualdades de gênero" no orçamento público, através do Planejamento Plurianual 2004-2007. Essa apropriação do discurso de gênero pressuporia três dimensões:

1. Incorporação da categoria gênero em todas as fases de do planejamento de políticas públicas, em qualquer área e nível do governo; 2. Incorporação da abordagem de gênero na prática dos gestores de políticas públicas; 3 . Disseminação de novos valores culturais e políticos para a sensibilização da população quanto às desigualdades de gênero. (BANDEIRA, 2004).

Neste contexto, foi instituído no Brasil o chamado "Feminismo Estatal-Participativo", que consiste na reunião de lideranças feministas da academia, dos movimentos sociais, de representantes da sociedade civil para discutir temas de interesse para as políticas governamentais. De acordo com Sônia Alvarez e Marlise Mattos (2018), ao menos 112 conferências nacionais foram organizadas pela Secretaria de Políticas para as Mulheres em 2004, 2007, 2011 e 2016. Essas conferências envolveram entre 200 e 300 mil mulheres em debates sobre políticas feministas, antirracistas, antilesbofóbicas e outros ideais e agendas de inclusão e promoção de justiça social. 
No rastro desses movimentos foram desenvolvidas políticas públicas em diversas áreas, inclusive na área educacional. Especialmente no caso do esforço para empreender uma mudança de perspectiva do conjunto de servidores públicos, programas de formação foram implementados para professores e para gestores da rede pública do ensino básico a partir de 2006. Refiro-me especialmente aos cursos "Gênero e Diversidade na Escola" e "Especialização em Gestão de Políticas Públicas de Gênero e Raça". Ambos os projetos foram implementados em larga escala, em todas as regiões do país, através da metodologia da educação semipresencial e da estrutura da Universidade Aberta do Brasil ${ }^{6}$. Estas inciativas tinham em seu escopo a premissa da interseccionalidade, ao abordar as temáticas da diversidade sociocultural, das relações de gênero e raça e da sexualidade. As duas inciativas foram desenvolvidas por núcleos de estudos de gênero das universidades públicas brasileiras e tiveram como base a literatura feminista, discutida em cursos de graduação e pós-graduação.

Diversos estudos empíricos foram desenvolvidos, desde então, para entender o impacto dessas políticas na percepção da burocracia do Estado sobre as desigualdades de gênero, através de seus servidores, sejam professores, diretores ou gestores públicos. Muito foi aferido de positivo e de negativo nesta empreitada da articulação academia $x$ políticas públicas. Diferentes análises mostram também o crescimento dos estudos de gênero em áreas acadêmicas que não necessariamente tem como escopo principal a reflexão de gênero, como a educação e a administração ${ }^{7}$. Pode-se afirmar, com certa cautela, que as ações empreendidas objetivaram firmar um novo pacto educacional, voltado às questões da desigualdade de gênero. Fato é que o tema "gênero"

\footnotetext{
${ }^{6}$ Estrutura da Capes (Coordenação de Aperfeiçoamento de Pessoal de Nível Superior) para viabilização de cursos de graduação e pós-graduação a distância, por universidades públicas de todo o país.

7 Uma análise importante de impacto do Curso GDE está no relatório "Gênero e Diversidade na Escola: Avaliação de processos, resultados, impactos e projeções", publicado em 2017 pela UERJ/ÇEPESC.
} 
passou a ser mais falado e discutido na sociedade brasileira. Talvez um resultado difícil de ser previsto seria o uso deste conceito de forma distorcida e sensacionalista, e reinterpretado como uma cruzada das mulheres em busca de privilégios ou, na associação com a sexualidade, que a população LGBT tivesse como objetivo eliminar a dita "família tradicional brasileira". Tal distorção faz ainda hoje bastante estrago na luta feminista pela igualdade de oportunidades e na efetivação de direitos.

Com a ascensão de um projeto de poder de extrema direita à Presidência da República, aparentemente conservador nos costumes, defensor de uma "moralidade perdida", centrada nos papéis rígidos e imutáveis de mulheres e homens, baseados em dogmas religiosos, os estudos de gênero e a própria ciência, progressistas e antifamília, na visão da nova gestão, passaram a ser rechaçados e esvaziados. Entretanto, o investimento formal das políticas para as mulheres continua existindo. A antiga Secretaria de Políticas para as Mulheres foi reorientada e passou a se chamar Ministério da Mulher, da Família e dos Direitos Humanos e apresenta uma total reorientação das políticas implementadas pela gestão anterior, agora totalmente voltada para a mulher, no âmbito da família conservadora e religiosa e, por definição, excludente e imutável. $\mathrm{O}$ atual ministério está em seu segundo ano de trabalho, entretanto há pouco publicado sobre o planejamento das ações e sobre os projetos implementados, para além de documentos formais onde as informações sobre a atuação do ministério são escassas. Contudo, a atual ministra, em seu discurso de posse afirmou "o Estado é laico, mas esta ministra é terrivelmente evangélica". Partindo do pressuposto de que a Constituição Brasileira de 1998, em seu artigo 5a, assegura a liberdade religiosa e o tratamento igualitário para qualquer tipo de crença ou convicção filosófica e política, a veiculação da religião que a gestora pública professa é irrelevante no âmbito do serviço público. Seu intento pode ser interpretado como uma indicação de rompimento na política de gênero empreendida até então, baseada no 
questionamento do patriarcado e na superação da submissão feminina através de políticas públicas viabilizadas pelo feminismo estatal.

Para finalizar, retomo o diálogo com Claudia Fonseca (1995), em sua reflexão sobre a produção de conhecimento das Ciências Sociais acerca dos valores da nossa própria sociedade, especialmente sobre família na modernidade:

Não faz sentido liberar-nos dos mitos do passado para logo ceder as novas receitas da modernidade. $\mathrm{O}$ mito do passado, em geral, não é nada mais do que um valor que caducou. Para repudiá-lo, abraçamonos aos valores da atualidade. Sendo seres sóciohistóricos, nunca estamos acima dos valores mestres da nossa época. Mas, enquanto pesquisadores, temos a obrigação de tentar o impossível - superar os limites dos nossos próprios (pré-)conceitos (FONSECA, 1995, p. 87).

A distinção entre carreiras ditas femininas ou masculinas reflete a associação direta entre o que é visto como um fazer científico, adquirido no plano da cultura e algo pensado como cuidado, atributo historicamente feminino e tido como "natural", que influencia e restringe as possibilidades de carreiras que mulheres e homens escolhem trilhar. Tal cenário apresenta muitos desafios para o feminismo e para a ciência, pois demanda, em uma primeira reflexão, novas perspectivas para as políticas públicas e sociais na área de educação, assim como para a divulgação científica.

\section{Referências}

ALVAREZ, Sonia; MATOS, Marlise. Apresentação. Quem são as mulheres das politicas para as mulheres no Brasil. Feminismo estatal participativo brasileiro. Porto Alegre: Ed. Zouk, 2018. v. 1.

ARAÚJO, Clara; PICANÇO, Felícia; CANO, Ignácio; VEIGA, Alinne. Evolução das percepções de gênero, trabalho e família no Brasil: 2003-2016. Gênero, Família e Trabalho no Brasil do Século XXI - mudanças e permanências. Gramma Editora: Rio de Janeiro, 2018. 
BANDEIRA, Lourdes. Fortalecimento da Secretaria Especial de Políticas para as Mulheres. A transversalidade da perspectiva de gênero nas políticas públicas. Brasília: Cepal, SPM, 2004.

BARRETO, Andreia. A mulher no ensino superior: distribuição e representatividade. Cadernos do GEA, Rio de Janeiro, n. 6, jul./dez. $2014 . \quad$ Disponível em: http:/ / flacso.org.br/files/2016/04/caderno_gea_n6_digitalfinal.pdf . Acesso em: 20 ago. 2020.

BIROLI, Flávia. Agentes imperfeitas: contribuições do feminismo para a análise entre autonomia, preferências e democracia. Revista Brasileira de Ciência Política, n. 9, p.7-39, 2012.

BOURDIEU, Pierre. A dominação masculina. Rio de Janeiro: Bertrand Brasil, 1999.

CARVALHO, Layla Pedreira. A SPM e as políticas para as mulheres no Brasil: saltos e sobressaltos em uma institucionalização das demandas das agendas feministas. In: MATOS, Marlise; ALVAREZ, Sonia (Org.). Quem são as mulheres das politicas para as mulheres no Brasil. Feminismo estatal participativo brasileiro. Porto Alegre: Ed. Zouk, 2018. v. 1.

CARVALHO, Marília Pinto de. Mau aluno, boa aluna? Como as professoras avaliam meninos e meninas. Revista Estudos Feministas, v. 9, n. 2, p. 554-574, 2001. (Dossiê Gênero e Educação).

CRENSHAW, Kimberlé. Documento para o encontro de especialistas em aspectos da discriminação racial relativos ao gênero. Revista Estudos Feministas, v. 10, n. 1, 2002.

Decifrar o código: educação de meninas e mulheres em ciências, tecnologia, engenharia e matemática (STEM). - Brasília: UNESCO, 2018 https:/ / unesdoc.unesco.org/ark:/48223/pf0000264691 Acesso em 20 de agosto de 2020.

FONSECA, Cláudia. Amor e família: vacas sagradas da nossa época. In: RIBEIRO, Ivete; RIBEIRO, Ana Clara T. (Org.). Família em processos contemporâneos: inovações culturais na sociedade brasileira. São Paulo: Loyola, 1995.

GOZALES, Lélia. A categoria político-cultural da Amefricanidade. BUARQUE DE HOLANDA, Heloísa (Org.). Pensamento feminista: conceitos fundamentais. Ed. Bazar do tempo: 2019. 
GUEDES, Moema de Castro. A presença feminina nos cursos universitários e nas pós-graduações: desconstruindo a ideia da universidade como espaço masculino. História, Ciências, Saúde Manguinhos, Rio de Janeiro, v. 15, supl., p.117-132, jun. 2008.

GUEDES, Moema de Castro; AZEVEDO, Nara; FERREIRA, Luiz Otávio. A produtividade científica tem sexo? Um estudo sobre bolsistas de produtividade do $\mathrm{CNPq}^{*}$. Cad. Pagu, Campinas, n. 45, p. 367-399, dez. 2015.

Disponível em: http:/ / www.scielo.br/scielo.php?script=sci_arttext\&pid=S010483332015000200367\&lng=en\&nrm=iso. Acesso em: 30 ago. 2020.

HIRATA, Helena \& KERGOAT, Danièle. Novas configurações da divisão sexual do trabalho. Cadernos de Pesquisa, v. 37, n. 132, p. 595609, 2007.

HIRATA, Helena. Gênero, classe e raça: Interseccionalidade e consubstancialidade das relações sociais. Tempo Social, 2014.

KERGOAT, Danièle. Dinâmica e consubstancialidade das relações sociais. Novos Estudos - CEBRAP, n. 86, 2010.

LOURO, Guacira Lopes. Gênero, sexualidade e educação. Petrópolis, RJ: Vozes, 1997.

MACHADO, Cecília; NERI, Marcelo Côrtes; PINHO NETO, Valdemar Rodrigues de. Educação, ciclo de vida e desigualdade de gênero no mercado formal brasileiro. FGV, 2017. 